\title{
Diffusing scientific knowledge to innovative experts
}

\section{Svend Tveden-Nyborg, Morten Misfeldt, Birte Boelt}

\begin{abstract}
Communicating science to scientists works well thanks to well-defined communication structures based on both printed material in peer-reviewed publications and oral presentations, e.g. at conferences and seminars. However, when science is communicated to practitioners, the structures become fuzzy. We are looking at how to implement Web2.0 technologies to Danish seed scientists communicating to seed consultants, agricultural advisors, and seed growers, and we are met with the challenge of securing effective knowledge diffusion to the community. Our investigation's focal point is on Rogers' theoretical framework "Diffusion of Innovation" (DOI), as we look at how DOI may affect the Danish seed industry if science communication is redesigned in accordance with the framework. During our project workshop, participants recognized trends and characteristics from DOI in the Danish seed community and argued for more collaboration between scientists and practitioners. This can be done by implementing fast-learning via online website, but it needs to be assisted by slowerpaced face-to-face learning to lessen the risk of a digital knowledge divide within the community.
\end{abstract}

\section{Introduction}

Today scientists traditionally communicate their validated research findings in peerreviewed articles appearing in international scientific journals; sometimes they also communicate their findings in specialized magazines - especially within the fields of applied sciences; and in some cases they arrange seminars with the industry where knowledge is transferred. However, as technology evolves (e.g. Web 2.0 technologies) there is a demand/ambition for improved communication between end users and researchers. In the current paper we want to investigate the opportunities in developing online communication tools to meet these needs.

As early as 1943 Ryan and Gross laid the foundation for the theoretical framework 'diffusion of innovation' (DOI). ${ }^{24,26,27,31}$ In particular they looked at how American corn growers changed practice to hybrid seed corn following American scientists' findings explaining why some farmers adopted the hybrid seed corn, while others did not. ${ }^{23,24}$ The corn case has similarities with the findings from the Danish seed investigation from $2010,{ }^{30}$ investigating how seed consultants, agricultural advisors, and seed growers (here- 
inafter referred to as consultants, advisors, and growers) disseminated seed knowledge from seed scientists (hereinafter referred to as scientists). The latter indicated that the majority of Danish growers' basic needs for knowledge are covered by their consultants and that a small group of more innovative growers request more specific information from the involved scientists.

Seed production is a specialized branch of crop production since specific rules apply as regards genetic and physical purity, germination percentage, etc. Only certified seed production is carried out in Europe, meaning that there must be a contract between the farmer and the seed company. In order to meet the quality criteria, the seed company provides assistance to the seed growers through its consultants.

Using the Danish seed community as a case, we want to investigate the consequences of applying DOI with scientific communication. Is it possible to fuse the outlines from the corn and seed cases together and thus improve dissemination of scientific knowledge from the scientists to the consultants and the growers in the Danish seed community?

We base the investigation on a qualitative workshop approach in which we investigate what constitutes good collaborative knowledge practice in the Danish seed community and how the participants together view an optimal communication flow from the scientist to the grower. Furthermore we use Rogers' Diffusion of Innovation (DOI) - defining diffusion as the process by which an "innovation is communicated through certain channels over time among the members of a social system" 23 - to discuss similarities between how American corn growers in the 1940's and Danish growers today learn about new scientifically proven practices.

\subsection{Developing research electronic tools for knowledge dissemination in the Danish seed community}

The overall intention of our work is to improve web communication between researchers and end-users. The work is partly based on an interview project in $2010,{ }^{30}$ which revealed a general demand from consultants, advisors, and growers for an online knowledge tool in which they could find scientific knowledge on seed production. In addition a few growers expressed needs for closer collaboration with the scientists. In 2011 we arranged a workshop discussing future scenarios for a communication platform and in which we introduced DOI for the community. The results from the interviews and the workshop were formed into the design of a website that has been launched in the fall of 2012. It takes a lot of effort from both hosts and visitors to uphold a website with up-to-date information. Therefore one aim with the workshop was to form an inspiring discussion among the participants with regard to their demands and ideas on designing a future shared knowledge tool on seed production. 


\subsection{Research questions}

This paper is based on Rogers' theoretical framework on DOI and addresses the following questions:

- What are the benefits and drawbacks of applying Rogers' Diffusion of Innovation MODEL on the Danish seed community?

We want to find out if DOI is a suitable theoretical framework for the Danish seed community - e.g. how can one compare science communication with innovation as described by Rogers?

DOI describes five user profiles of an adopter ranging from innovators and early adopters to early majority, late majority, and laggards. We want to find out what implications this user diversion may bring if used in our specific communication situation.

- In what way will we be able to use Rogers' theory in our future communication design?

Looking at methods to develop new communication tools for disseminating scientific knowledge to practice, we want to investigate ideas to overcome the challenge of providing scientific knowledge to knowledge intensive communities that at the same time constitute mixed atypical knowledge workers of all ages and academic backgrounds.

\section{Theoretical considerations}

We have chosen to use Rogers' framework in this paper to understand learning, knowledge, and communication in multilateral networks. Many scholars have worked with looking at the understanding and promotion of behavioral change. Particularly Rogers' pioneering work on the diffusion and adoption of innovation ${ }^{22,23}$ partly based on Ryan and Gross' field work from 1943 has been widely accepted.

According to Rogers 23

"Diffusion is the process by which an innovation is communicated through certain channels over time among the members of a social system".

The diffusion theory describes the adoption pattern and how an innovation becomes a success. The theory is rather a tool to describe the spread of innovation than a tool to explain or predict adoption patterns.

\section{Innovation}

Rogers defines innovation as an idea, practice, or object that is perceived as new by a target group. ${ }^{19,23}$ People will adopt an innovation if they believe that it will improve the 
usefulness in their daily work. Provided that decisions are not authoritative or collective, every member of a social system faces his own innovation decision, following a fivephase model: knowledge (exposure and understanding, reducing uncertainty); persuasion (forming a favorable or adverse attitude); decision (commitment to adopt or reject); implementation (use); and confirmation (reinforcement because of positive outcomes). ${ }^{23}$

What makes the innovation successful or not comes down to the point of whether or not it has proven itself worthy for adoption or rejection by the members of the community. In the end the final decision is left to the individual; based on the information he has experienced will he be committed enough to adopt the new change with the risks that it may involve?

\section{Communication channels}

Although mass media may play an important role in the early awareness stage of diffusion, interpersonal communication more often occurs during the actual decision process. "A person evaluates a new idea and decides whether or not to adopt it on the basis of discussions with peers who have already adopted or rejected the innovation". ${ }^{21}$ This dependency on peers shows the importance of opinion leaders in the actual innovation process. Opinion leaders have more credibility with decision makers due to established mutual relations.

One of the ways in which change can happen is through what Rogers call a change agent; the agent must be capable of developing a quest for change with the grower. The change agent must be able to diagnose problems and motivate interest for the innovation. Furthermore, he must create an intention for change with the growers, and he must translate intention into action.

Time

Rogers' model also introduces a time dimension and classifies the adopters into five categories classifying individuals within a social system on the basis of their innovativeness: innovators, early adopters, early majority, late majority, and laggards. ${ }^{23}$

- Innovators (or pioneers) are the first to adopt an innovation. They are willing to take risks, youngest of age, have the highest social class and great financial latitude, are very social, and have close contact to scientific sources and interaction with other innovators.

- Early adopters constitute the second fastest category of individuals who adopt an innovation. Here you find the highest concentration of opinion leadership compared with the other four categories. They are young, have higher social status, financial latitude, and higher education than late adopters. 
- Early majority individuals consult an earlier adopter before they make up their mind to adopt an innovation. They have above average social status, are rarely opinion leaders, and spend more time considering when to adopt than innovators and early adopters.

- Late majority individuals will adopt an innovation after the average member of a society. They are typically skeptical about an innovation, have below average social status, possess very little financial latitude, and are almost never opinion leaders.

- Laggards are the last to adopt an innovation. They typically have an aversion to change agents and tend to be advanced in age. They are tradition bound and likely to have lowest social status and least financial latitude. They are only in contact with family and close friends.

It takes time to implement an innovation into a society. The concept about "critical mass" at which a trend catches fire finds its origin in DOI. The most essential contribution deals with the fact that members' decisions to adopt to a great extent are dependent of other members' decisions to adopt. Empirical data - ranging from hybrid seed corn to modern mathematics, to the snowmobile, and to antibiotic drugs for HIV/AIDS prevention ${ }^{23}$ all show the same meaning: that successful diffusion of innovation always forms an $\mathrm{S}$ curve (see figure 1). What curves the form into an $\mathrm{S}$ is the time that people spend making their innovation decision: some individuals make up their mind fast and other individuals decide later on; some individuals need more information while others are more open to changing work patterns. ${ }^{13,20}$

The critical point marks the opinion leaders' adoption. Well-informed opinion leaders communicate their acceptance or rejection on an innovation based on the innovators' experiences to the remaining part of their personal network. The majority respond by quickly following suit, adopting the innovation. Thus, diffusion of an innovation largely depends on a surprisingly small fact: whether or not the opinion leader will vouch for the innovation.

\section{Social systems}

Social systems can be characterized as either homophilous or heterophilous, where homophilous systems are characterized by members who are alike and sharing similar sociocultural characteristics in comparison with heterophilous systems characterized by people with different backgrounds. In human communication the exchange of ideas occurs more often among homophilous people, because people are more comfortable with others if they share similar characteristics; homophilous relations and effective communication contribute to each other. ${ }^{23}$ However, homophilous relations carry with them invisible barriers to dissemination of innovation, as their perception and interaction with each other only spreads horizontally. ${ }^{23}$ In other words, homophilous relations accelerate diffusion 
that complies with familiarity and thus a tendency toward system norms, while at the same time stunts the dissemination of innovation. People and ideas that deviate from the norm are often regarded as strangers and thus undesirable. Often, opinion leaders in homophilous systems avoid adopting innovations in the hope of protecting their opinion leadership. $^{23}$

Contrary, heterophilous social systems try to encourage change from system norms. Here it is more the interaction between people with different backgrounds which indicates a great interest in getting exposed to new ideas. These systems have innovative opinion leadership because they want to innovate. ${ }^{23}$ For heterophilous systems, change agents can concentrate on the most elite and innovative opinion leaders and the innovation will leak out to the non-elite. If an elite opinion leader is convinced of adopting an innovation, the rest will show excitement and willingness to learn and adopt. The domino effect will start with enthusiasm rather than opposition. ${ }^{23}$

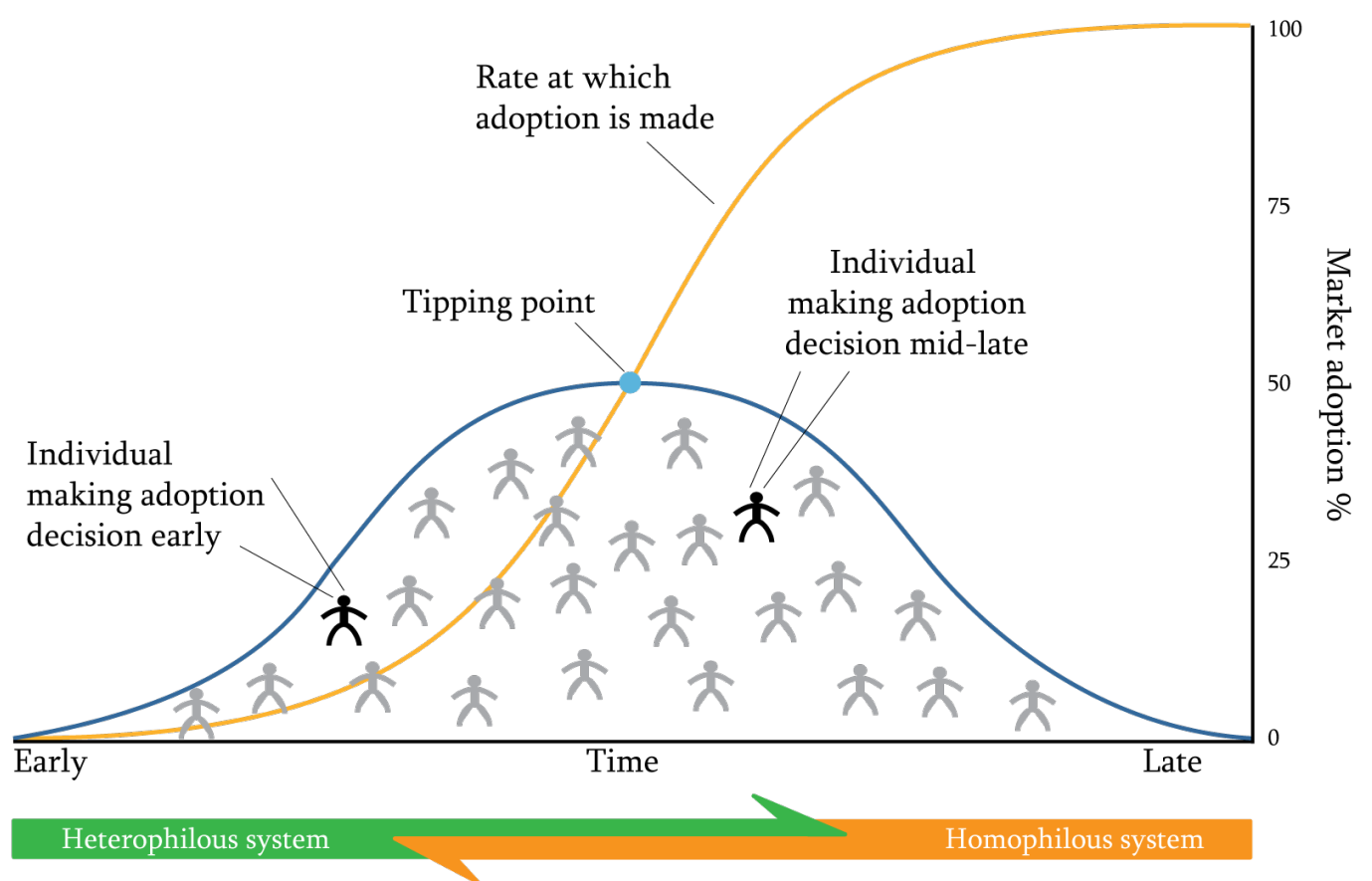

Figure 1. The diffusion of innovation - Seen from a time aspect with early adopters to the left, and slower and more suspicious adopters to the right.

Given that people are on average averse to risk, the uncertainty will often result in postponement of the decision making until further evidence can be gathered. However this is not the case for everyone. Every single innovation decision is basically framed by personal attribution and this diversity between individuals is what makes diffusion possible. 
The point is that Rogers focuses on the impact of networks, social systems, and communication structures on the diffusion of innovation. The members of a social system must develop and share information between one another and thereby reach a common understanding of the possibilities of the innovation in question.

Both Rogers and DiMaggio conclude that the more cosmopolitan and affluent a group of people are, the greater interest they will have in taking an innovation to heart. ${ }^{9,23,31}$

\section{Methods}

\subsection{Data basis and location}

A total of 12 persons were invited to take part in the workshop. As we wanted to set up matrix groups in the third session, the number of participants was limited to the number of scientists, as we wanted to set up the groups with a balanced symmetrical distribution among the professions. Thus, we decided to set up the groups with one individual from each profession. Four consultants were selected from the two main seed companies operating in Denmark (DLF-TRIFOLIUM A/S and Hunsballe Frø A/S). The four consultants (chosen from stratified samling ${ }^{5}$ ) were asked each to suggest one of their own growers who was successful in his trade (snowball sampling. ${ }^{5}$ ) Finally, four scientists working with seed research were invited (from convenience sampling..$^{5}$ ) All potential participants received an open letter invitation in which the purpose of the workshop was listed, and by accepting the letter they subsequently acknowledged taking active part in the workshop.

\section{Description of location and participants}

The workshop was held on March 312011 at the Danish School of Education under Aarhus University, (DSE-AU, Emdrup, Copenhagen). In addition to the 12 consented participants (4 consultants, 4 growers, and 4 scientists) a chairperson and two observers participated in the event. The Chairperson was assigned to take the role of facilitator, and was thus well prepared to address or redirect group discussions in the event of stalling. See figure 2 showing images from the workshop.

Furthermore, two scientists, two consultants, and one grower had participated in the interview project in 2010, and thus their anticipation of knowledge sharing was already known to the authors of this article. For the sake of confidentiality the names of the participants have been kept anonymized.

\subsection{Workshop set-up}

The workshop was set up in four parts: 


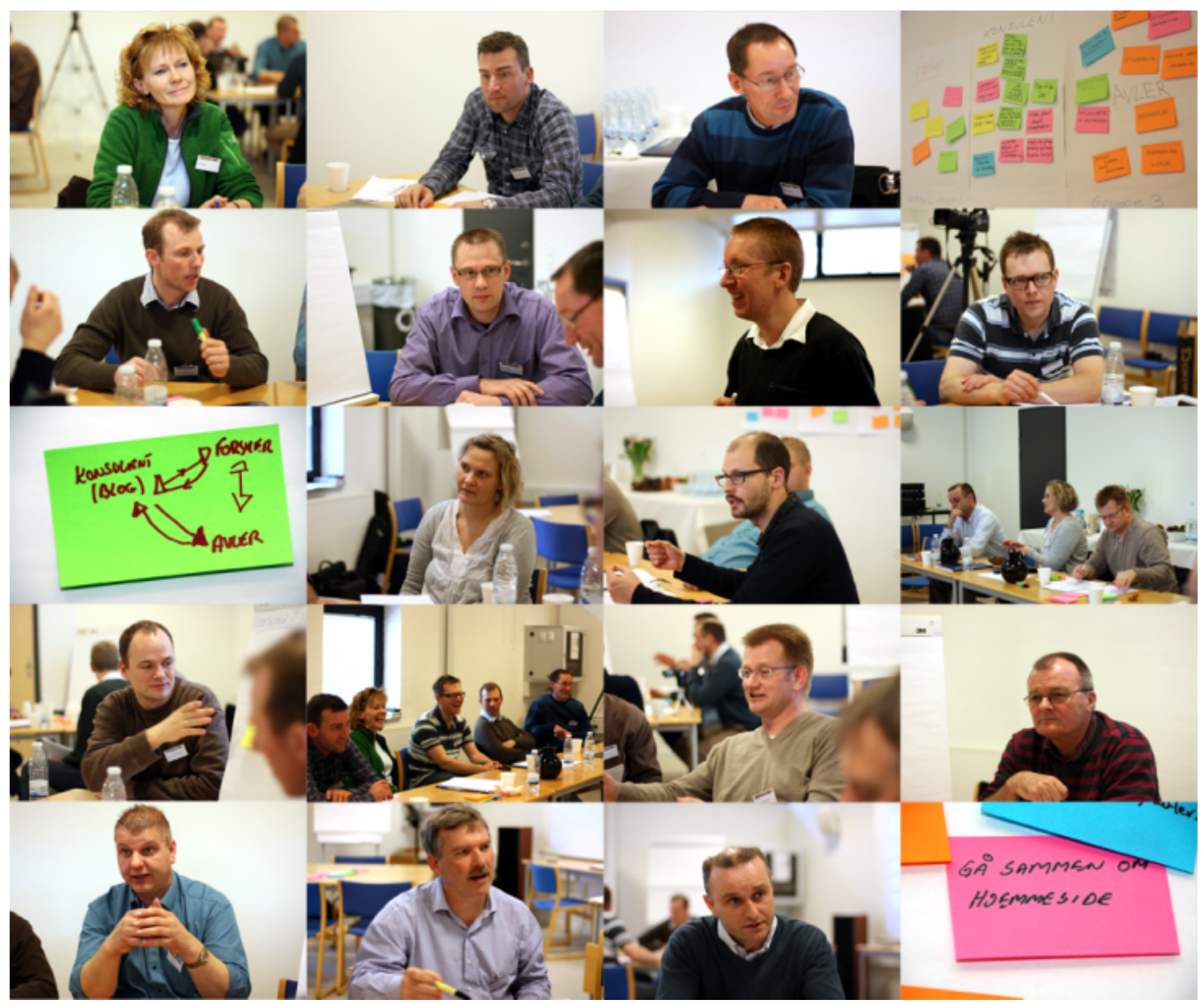

Figure 2. Moments from the workshop showing the participants taking full part in the lively discussions.

1. Introduction: the participants were introduced to each other and to the conclusion from the preceding interview project from 2010. A brief overview was presented of a selected subset of theoretical considerations in knowledge dissemination among communities of practice, including Wenger's communities of practice, ${ }^{11,12,15,32-37}$ which was used in the interview project in 2010, and Rogers' diffusion of innovation. ${ }^{1,13,14,16,17,19,23,27-29}$ Furthermore the participants were introduced to two different cases (medical science versus education science) exploring differences in practice - namely medical science involving both medical staff and researchers in a collaborative community versus education science with a significantly larger gap between science and practice.

2. First session: participants were assigned to groups based on professions to build up common definitions and concepts of how one - being either a grower, consultant, or 
a scientist - observes the knowledge flow and/or the knowledge challenge within the seed community. These different starting points would aid the participants later in the workshop.

3. Second session: four matrix groups were formed, each consisting of one grower, one consultant, and one scientist. The first task was to present their professional views on knowledge dissemination (the outcome from the first session) to their group members. The next step was to discuss the content of a future workshop free of rules and restrictions in which only imagination set the boundaries. The four groups began discussing three challenges and strengths that they found most preeminent when disseminating knowledge in the seed community. The aim of the future workshop was to let the participants create four radical suggestions of knowledge dissemination in the future and present and discuss their suggestions in plenum.

4. Third session: using the presentations from the second session as a starting point the participants discussed how the four radical suggestions could be carried out under the theme "How can the scientists' knowledge contribution come into play to create innovation in the Danish seed community?". The aim of the third session was to set up the framework of a workable knowledge dissemination prototype together with descriptive words on the participants' expectations of the prototype — how will it strengthen the seed community?

\subsection{Collection of data}

All work groups were issued with large $508 \mathrm{~mm} \times 584 \mathrm{~mm}$ post-it boards and small colored post-it pads to write comments on. After the workshop the four post-it boards including comments were collected and digitalized for further analyses. See figure 3.

Prior to the workshop all participants had agreed to be recorded by camera throughout the workshop. Four HD video cameras were set up recording the workshop from multiple angles, giving the advantage of simultaneous recordings for later transcription and analysis.

\subsection{Data analysis}

The recorded video material, together with the large post-it boards, was analyzed using the software program NVivo9 (QSR International, Australia). First, 14 hours of video recording were transcribed in NVivo9; secondly, the contents from the post-it boards were uploaded to NVivo9 and also transcribed.

Initially, the workshop data were explored to obtain a general overview. Secondly, the transcribed text (including both video transcription and transcribed post-its) was divided into segments of information which were then labeled with nearly 100 codes. In the 


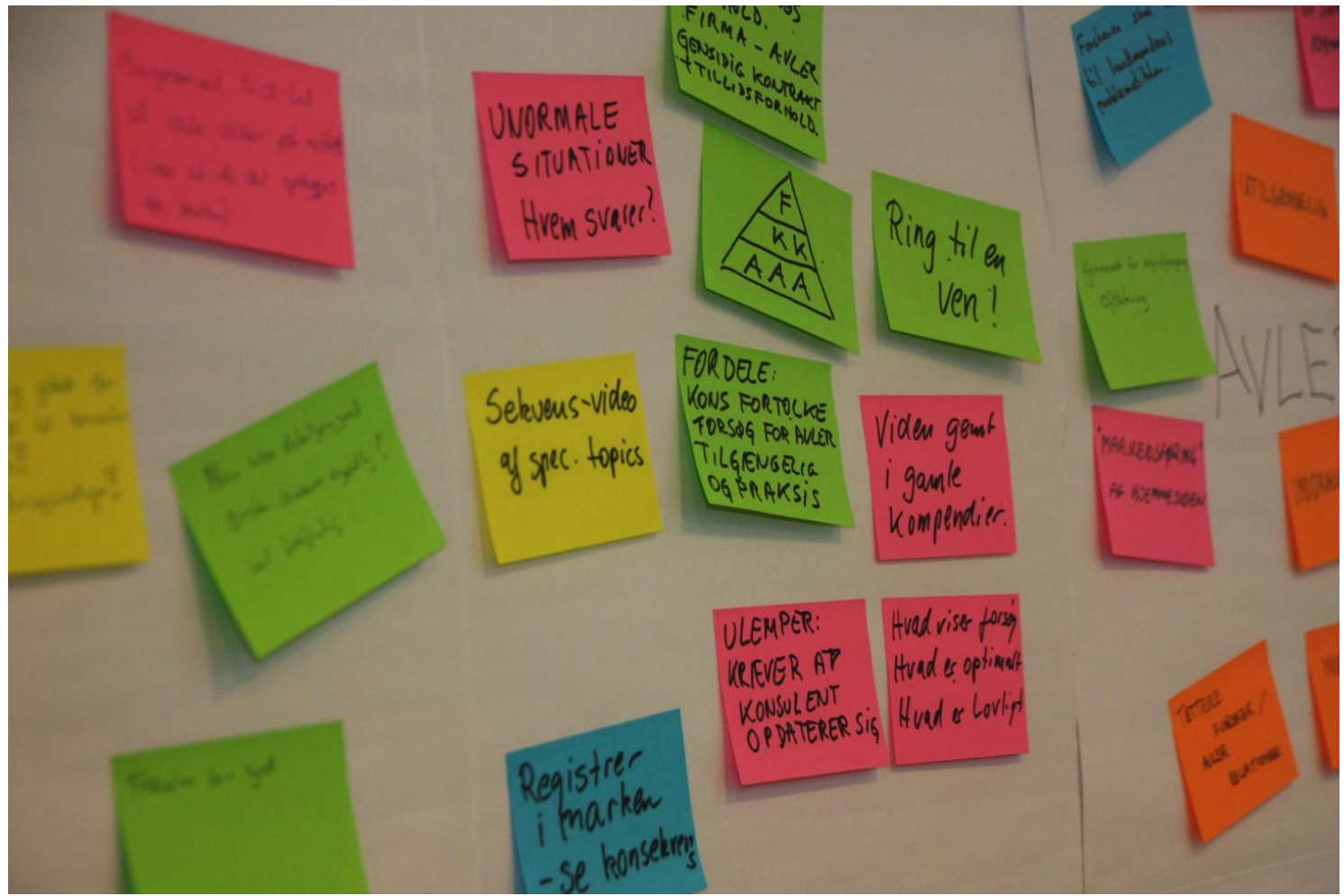

Figure 3. Collection of post-its from the workshop. In the current view are post-its from scientists, consultants, and growers.

third round of analysis the 100 codes were investigated and narrowed down to 20 overall codes reducing overlaps and redundant coding. The transcribed data were then reanalyzed using the 20 codes to see if they covered all aspects or not. When satisfied, we continued collapsing the codes into six overall themes. Theming the codes was carried out in a manner similarly to the third round process aggregating the codes into six themes or categories. See table 1 for details. These six themes would turn out to be topics that were especially discussed among the participants.

\subsection{Consequences and issues with a qualitative approach}

By choosing a qualitative approach to corpus analysis adds a limiting factor to the scientific result in that the findings cannot be extended to a wider population with the same degree of certainty that quantitative analysis can. Qualitative analyses are not tested to discover whether or not they are statistically significant or simply due to chance. However, the qualitative method allows for research to reflect and understand the complexity of a particular phenomenon. ${ }^{5,8}$ As "all research is interpretive and the researcher selfreflects about his or her role in the research, how he or she is interpreting the findings, and 

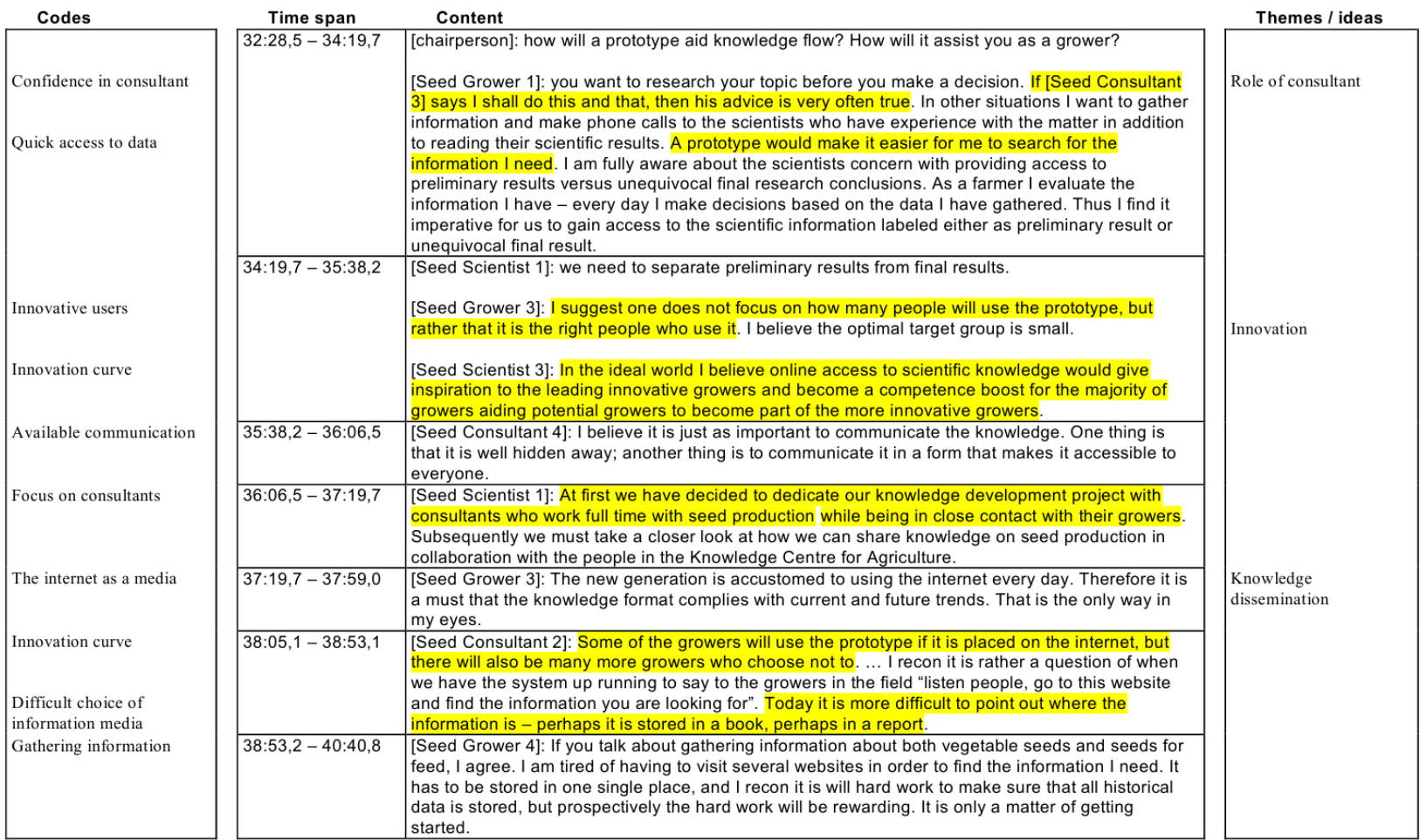

Table 1. An example on NVIVO9 transcription taken from the recorded video data during the future workshop in session two. Codes in the first column represent the highlighted content text, and the themes are represented in the last column. Note that the text examples in their original form were in Danish.

his or her personal and political history that shapes his or her interpretation", 5 accurate and credible analyzes are of utmost importance.

Another limiting factor to the project has been the selection of participants for the workshop. The selection for the workshop was based on the idea that all participants should have a clear idea about knowledge sharing in the Danish seed community. The participants agreed in many aspects of the discussions throughout the day regarding how to strengthen dissemination of knowledge in the seed community. This could be caused by the high demand for more knowledge by all the participants. In addition the growers were appointed by their consultants and this process could also be questioned as to why they appointed one grower from the other; as it turned out all four participating growers were successful with their work and spent more time than other growers (learned from previous science project) searching for new scientific information. Perhaps one would have reached a more differentiated result had the participants in the workshop represented a broader variety; rogers describes five different classifications of people when innovations are adopted (see page 2) of which the involved participants represented the first two classifications, the innovators and the early adopters. 


\section{Results}

An analysis of the many post-it data and the recorded video material revealed six overall themes discussed during the workshop. The themes are as follows:

1. The strengths of the seed community

2. The influence of the innovation curve for the growers

3. The consultant as an intermediary between the growers and the scientists

4. Dialogue and collaboration between scientists and growers

5. The current form of scientific knowledge

6. Electronic knowledge dissemination

During the entire workshop the participants all worked from the concept that one end product of the workshop would be to create some sort of electronic communication tool on the Internet. Thus, electronic knowledge dissemination was on everybody's mind throughout the workshop.

\subsection{Ad. 1. The strengths of the seed community}

The participants in the workshop all agreed that there is a well-organized information flow from the scientist to the consultant and from the consultant to the grower. The scientist is in dialogue with the consultants over the course of the year during various formalized science program activities such as summer and winter meetings, planning meetings, and project meetings. They confirmed the findings from the preceding interview project from $2010 .{ }^{30}$

Seed Scientist 1 described the close relationship between the scientists and the consultants "In fact we have blind faith in the work the consultants do when they process and adapt the knowledge we have provided them with and forward it to their growers."

At the same time the consultants inspect the growers' fields during high season and thereby get a very good insight in current and arising problems.

Finally, the growers benefit from local network activities (experience exchange groups, "twelve-men" associations, and neighboring communities) in which the growers may be inspired by each other's methods and personal experiences.

Seed Consultant 3 expressed it thus that "today the growers use their own grower networks to evaluate and discuss normal problems. In addition they have their advisors to assist with designing spray strategies. And finally they have us consultants to discuss more specific problems with relation to seed production."

Seed Consultant 3 continues "a major advantage with the current activities with the scientists is the forum in which you take part. Here you meet a lot of colleagues from 
all over Denmark, who are also in possession of useful knowledge, and with whom you afterwards can make a beneficial phone conversation if you experience new challenges".

\subsection{Ad. 2. The influence of the innovation curve for the growers}

The innovation curve was introduced as an opening to the workshop and refers to the theoretical framework regarding diffusion of innovation by Rogers. Over the course of the workshop innovative growers were referred to as "the $10 \%$ most talented growers". However, the data from the workshop cannot confirm or reject whether this number is fair or not, but all the participants used the ratio as a means to refer to the group of innovative growers in Denmark.

According to Seed Grower 2, "The common denominator for the top $10 \%$ most successful growers is that they are eager for knowledge. They know all sorts of data. They prefer that the data are sorted so that they do not have to search too long. Therefore they will not be timid of the scientific data you can provide to them - they will grasp the part that they can use for themselves."

Seed Grower 3 made a small criticism regarding the focus on the innovative growers: "There will always be some out there who prefer to keep things to themselves and others who eagerly share their knowledge. It will always be like that. Experience exchange groups have a significant value that I believe you as scientists have not recognized before. It cannot be expressed. It is an ongoing process and I believe that if you provide new knowledge to these experience exchange groups, it will be disseminated from there."

An innovative grower's network was suggested as a common denominator for growers with an interest in dialogue with scientists. Networking between growers and scientists is also possible - parallel to the current network in which the consultant acts as mediator between the scientists and the growers. By doing so, the scientist would become better at understanding the grower's incentives to contact the scientist with his questions. The growers suggested that science should initially be placed among these innovative growers — this would strengthen the future implementations from the phased-out science projects among the growers.

\subsection{Ad. 3. The consultant as an intermediary between the growers and the scientists}

The consultants" role as "mediators between growers and scientists" is a great asset to knowledge dissemination to the growers in that the consultants acting as boundary spanners between the other two professions are able to interpret and pass on the scientists' science communication to the growers; especially to those growers who do not have the time or skill (e.g. English language proficiencies, and deficient understanding of scientific terms) needed to search for and understand the scientists' direct communication. 
"The consultants are very skilled in making their own conclusions on the research matters that we present to them at our annual meetings", Seed Scientist 3.

"If you want to make the research more useful, I believe it is vital that it passes through the consultants' filtering, so that in the end we get something that can be applied straight away in our production", Seed Grower 1.

However, the consultants' central role can only be carried through if they constantly keep their knowledge banks up-to-date. In return, the communication is simple and easy and thus shortening the span from science to practice. At the same time the scientists have confidence in the consultants' interpretation of their scientific results.

According to Seed Consultant 2 "the growers prefer to talk seeds with us consultants, as we have actual knowledge about their fields in that we frequently visit them."

\subsection{Ad. 4. Closer dialogue and collaboration between scientists and growers}

Closer dialogue and collaboration between scientists and growers were another central issue that emerged during the workshop and were influenced by a presentation during the introduction regarding knowledge flow, best practice and proof from the Danish medical science.

In particular the growers emphasized their wish for shortening the distance from growers' practical ideas to scientists' actual trials. Either by increasing the number of visits to the growers or by allowing the growers to call the scientists directly. However, the scientists opposed to this more straight forward network approach as explained by Seed Scientist 1, "We would not prefer that random people called us about seed matters, because first of all we would not be able to tell if this was a sudden ready-made idea or if was something that has been going on for quite some time. Secondly we have 4,500 growers and we would risk that we did nothing else but answered these phone calls."

In addition the growers discussed the possibilities for moving the scientific trials into on-farm experimentation. By involving the growers directly in the scientific work would increase the speed of scientific dissemination to the growers. It was a novelty for the scientists and consultants that the present growers to a great extent wanted a closer dialogue with the scientists and be able to verify the original set of scientific data. Seed Scientist 1 explained that "The scientists are uncertain about what kind of information the growers want, plus in what detail levels and form they want the data presented." Seed Consultant 4 pronounced during the evaluation, "it was a surprise to see the growers' needs to surpass the consultant... that was a novelty for me".

\subsection{Ad. 5. The current form of scientific knowledge is laborious to handle}

Apart from the growers' close dialogue with the consultants, the attending growers expressed their needs for useful information sources - they explained that they felt them- 
selves distanced from the actual scientific knowledge source. Today there are only scarce information sources with scientific content acting as alternatives to the consultants. Of these, the most commonly used are the articles that the scientists publish in the two seed periodicals "Tidsskrift for Frøavl" and "Frøavleren", together with the agricultural press media.

Several participants expressed challenges with using the agricultural press media as a communication tool to broadcast science to a larger audience.

"The scientists see a challenge in bringing 'business as usual' news to the public through the press. The press media prefer to write about matters that make headlines, and not necessarily write about recurring scientific results", Seed Scientist 2.

Seed Scientist 3 continued "The consultants are better at understanding and passing the 'news' story to the growers, which is not always passed on by the press media as their main concern is to sell newspapers. However a good story for the growers could also be that 'business is in fact still as usual' why he would not gain an excess yield by applying the method in question."

The scientists' press criticism was confirmed by the growers whose first criticism on the current set-up between growers, consultants, and scientists was not on any of the three but on the press media. "The press media's magazines are too thin, as they do not give us much detail on the matters they talk about. We learn too little from them.", Seed Grower 4.

Another criticism made by the consultants was that the scientific know-how is stored in printed reports given that the confidential reports which are sent out by the scientists in December are only published on paper.

"It is a disadvantage for us that all our knowledge is based on printed material in old compendiums", Seed Consultant 3.

This makes specific search requests difficult and time consuming as there is no specific index or search options. Seed Consultant 2 continues, "A new consultant needs to start from the bottom and build up his own knowledge by reading through all the books of instructions published since dawn of time."

\subsection{Ad. 6. Electronic knowledge dissemination}

Electronic knowledge dissemination was planned to be a central theme in both the introduction and the discussions during the workshop. Due to this and the fact that there is very limited scientific information on Danish seed production stored on the Internet, it was not a surprise that there was great support for the idea of creating one single database with all information regarding seed production in Denmark and with proper search functions.

Seed Grower 3 described the need for access to electronic knowledge "You cannot communicate specifically to growers as you do not know what they want to know. Therefore you have to create an online database so that the growers with a specific need can find what they are looking for." 
"The problem with communicating science to all growers is that a few of them would be able to see the possibilities and especially the limitations in our findings, whereas the greater part could easily risk misunderstanding our conclusions and cause severe damage when applying the research findings in their production." explained Seed Scientist 2.

Seed Consultant 1 continued, "The scientists' results are based on repetitive experiments in small 2 by 5 meter plots, but they are not always applicable on growers' 50 hectare fields. This is where we consultants pay our tribute with broad field experience in which we are able to relate science with practice and thus filter the scientists' messages to our growers".

\section{Discussion}

Overall, the workshop revealed a Danish seed community with a strong resemblance to American hybrid corn growers 65 years ago ${ }^{26}$ in that the participants recognized the characteristics of the DOI categories in the Danish seed community in addition to the concept of how innovations are diffused over time through various segments of a community. In addition, the workshop confirmed previous findings from 2010, namely that the consultants perform well as change agents mediating scientific knowledge primarily acquired through two annually meetings with scientists. One of the surprising elements in the workshop was the fact that there were growers who would like to gain access to the scientific data on which the consultants base their knowledge.

\subsection{Diffusing scientific knowledge to a community}

What had started out as an inspirational introduction to the workshop by drawing an analogue to Ryan and Gross's original data turned out to be central in the workshop debate, namely the significance of the diffusion of innovation for the workflow of scientific knowledge in the Danish seed community.

Everett Rogers' theoretical framework DOI that originated from Ryan and Gross' scientific work in 1943 describes how innovation spreads through a community over time. Rogers defines innovation as something new to a community, and for this article with our Danish seed community case focusing on the scientists' communication needs, we look at:

"innovation as an idea or new practice, based on new validated scientific knowledge"

which is new when targeted at the growers and consultants. This idea may originally have come from growers, consultants, or scientists, and its potential research value may have been discussed with all parties. However, the innovative part in the scientists' communication is the validating value that either confirms or rejects the ready-made assumptions about the original idea in the community with validated scientific proof. 
What makes this theoretical framework interesting for the Danish seed community is the fact that many different communication channels are available to the growers when it comes to information on seed production, but when you apply a filter on communicated scientific knowledge, the list of available communication channels is quickly narrowed down to just a few printed magazines plus the support by the consultants. Furthermore, a concern was brought forward by the participants during the workshop that the role of especially the seed periodicals reflects a selective content choice made exclusively by the editors. When you take this into account, it makes the consultant's role as active knowledge medium even more prominent when the consultants provide the growers with the latest scientific knowledge. The challenge for the scientists is to find a method that ensures access to scientific knowledge for both the consultants and the growers in a fast and direct way, either in the form of passive printed communication or active face-to-face communication.

Rogers' DOI model depicts five adopter categories with given estimates according to their size, based on the original investigation on American corn growers by Ryan and Gross. The workshop participants all recognized the five adopter categories from the seed community - not necessarily by name but more by the characteristics of each adopter role. However, our current data cannot confirm or reject similar Danish category estimates as we have not been able to investigate how the categories are represented among Danish growers. Therefore, when the people at the workshop discussed "the 10 percent innovative growers", they did not refer to the most innovative growers alone, but to the innovators' category as a whole. The idea of dividing a community into categories depending on their rate of innovation is very interesting from a science communication point of view and could be an interesting case for future research. As Seed Scientist 1 pointed out in the workshop, "The scientists are uncertain about what kind of information the growers want"; and knowing that not all individuals in a community take in new knowledge at the same pace, it can be difficult — if not impossible — to formulate a single uniform piece of information to all growers.

A suggestion for a future science communication model relating to the DOI theory would be to shift the scientists' primary focus to include both the consultants and the early adopters among the growers - i.e. focusing on the heterophilous social systems. Today the scientists are partly following this practice with their annual activities with the consultants, and there the academic level of communication is higher compared with the level in their popular science articles in farmers' periodicals. But by including the innovative growers - who by Rogers' definition are heterophilous in that they are interested in innovation and thus interested in attaining new scientific knowledge - the scientists can diffuse their knowledge to a wider range of people and thus speed up the initial implementation process among the growers.

According to the DOI diffusion curve of innovation, if the early adopters can be convinced of implementing the scientific innovation - i.a. via interpersonal networks - the 
remaining growers will follow suit over time. As Seed Scientist 1 described it during the workshop "Like a freight train the innovative growers will pull the other growers toward the innovation - if the reluctant growers can see that the first movers with the innovation have gained a contribution margin higher than their own, they will soon follow suit." Where the scientists today rarely communicate directly to and with farmers, a changing science communication focus would offer the early adopting growers information from both scientists and consultants, with the advantages and shortcomings that would follow from this model.

An advantage of the model is that diffusion of innovation to growers would shorten the time span starting with the scientists communicating their innovation and ending with the early adopting growers starting to implement the innovation into their work procedures.

On the other hand, a direct shortcoming is the risk that some growers will feel themselves more dissociated from the scientists if they are not part of the innovative group of growers capable of understanding the direct scientific communication. Furthermore, and perhaps more importantly, one should not overlook the value of the mediating consultants and advisors using their acquired skills to translate and interpret the scientific knowledge and transform it into a format that is more comprehendible for the majority of the growers.

Therefore it is important that the scientists soften this dissociation issue by relying on the consultants to function as mediating change agents together with opinion leaders among the growers all working as knowledge beacons disseminating information from the scientists to yet unenlightened growers, consultants, advisors and other people with interest in seed production.

According to Rogers "opinion leadership is earned and maintained by the individual's technical competence, social accessibility, and conformity to the system's norms. When the social system is oriented to change, the opinion leaders are more innovative." ${ }^{23}$ Furthermore, opinion leaders are found in all areas of a community and not necessarily among the early adopters or first movers meaning that they would be able to function as beacons spreading the innovation from opinion leader to opinion leader and from each opinion leader to his followers. If opinion leadership among the growers is vital for the spread of innovation in a community like the seed community, it brings with it a major challenge: what makes an opinion leader and how is he identified and mobilized? Is he the best grower with the highest seed yields or is s/he the least risk-averse grower taking in all new innovations without much hesitation?

\subsection{A model for online knowledge sharing}

Returning to the objective of designing a communications model, the workshop data have proved that DOI theoretical framework can be applied onto the Danish seed community. However, Wenger's theories about communities of practice (COPs) are directly applicable to the focus of this paper, ${ }^{30,33,37}$ defining COPs as "groups of people who share a 
concern, a set of problems, or a passion about a topic, and who deepen their knowledge and expertise in this area by interacting on an ongoing basis". ${ }^{33}$ The framework around COPs explains how different communities collaborate around a shared learning object. Furthermore several studies have shown that designed communication models can prove beneficial to a COP. For instance, Xerox saved hundreds of millions of dollars when their repairmen shared their experiences in a global database, ${ }^{3,4}$ and U.K. healthcare practitioners and researchers bridged research practice gaps through informal email network. ${ }^{25}$

When you set up a communications model, it is with the intention to support one or more COPs, and the available literature is packed with "one-size-fits-all" advice for organizations assuming that COPs are similar and can be treated as one-dimensional constructs. ${ }^{10}$ However, in order to nurture the community to its fullest potential, it is vital for the organization to understand the dimensions and constructs of the community. ${ }^{34,37}$ This will prove beneficial when potential stakeholders for the DOI communication model are addressed.

In the case of the Danish seed community, an analysis of the characteristics of the COP was made in 2010 identifying several challenges, of which one was access to new online scientific innovative knowledge. ${ }^{30}$ The Internet as a communication source of new innovation provides an informal source of knowledge to people in a COP, and furthermore it is independent of time and space benefitting both geographically dense communities and scattered communities - in the latter case consisting of isolated members without nearby colleagues to be inspired from.

Another advantage with the Internet as a communication source is the introduction of new technologies like social Web2.0 applications that are usually bi-directional, usergenerated or user-shaped, and of which the content is not published by a single source, but formed by the people using the site, nurturing the community. ${ }^{18}$ Web2.0 sustains and supports the mediating change-agent's / consultant's role when he communicates with his growers, as its potentially familiar presence makes it a reassuring knowledge medium to the grower. Studies from e.g. health care services have proved that informality have an effect with accelerating and broadening diffusion of innovation ${ }^{6,7}$ and have confirmed that social media ensure a broader social commitment in a COP.

An example of a successful Web2.0 platform is Wikipedia, which has become an important source of information to millions of Internet users. The name "Wikipedia" is a combination of the words wiki (a technology for creating collaborative websites, from the Hawaiian word wiki, meaning "quick") and encyclopedia. However, the reliability of Wikipedia is non-existent, as all users may write whatever they feel like; thus Wikipedia users need to be critical to the source of information. If a meritocratic 'science'-pedia was based on scientific skills and created around Web2.0 with validated scientific information, this would be a strong asset of support to the external mediating change agents, providing fast and easy online access, when needed, for an entire (seed) community. In addition this would provide the change agents and boundary spanners with direct access to the opinion leaders and peers scattered around in the community. 
The seed workshop in 2011 revealed two requests by the participating consultants and growers, namely a request for fast online scientific knowledge dissemination together with a closer slow-paced dialogue between the scientists and the growers.

An online science communication channel based on a social Web2.0 community platform would provide relevant scientific knowledge where and when needed. Therefore, easy access to knowledge will decrease time spent on searching for relevant information, and increase the rate at which individuals respond to adoption or rejection of a new innovation. A challenge will be to find a balance between the needs and desires of the stakeholders, as an online Web2.0 knowledge tool should create a mutual bi-directional knowledge flow between the scientists, consultants, and growers, and thus strengthen the seed community's innovation with optimal knowledge dissemination.

Providing fast online accessible scientific knowledge benefits the people accustomed to using online tools, disfavoring the people disadvantaged by online media - and thus risks creating a digital divide between the "online" and "offline" people. Focusing on both fast and slow communication media including both fast electronic knowledge media and slow face-to-face confrontation will diminish the risk of a digital divide between the fast learners and the slow learners.

Furthermore, not all knowledge can be articulated into an online database. There is a gap between what people know from articulated knowledge and what they do in reality, as actual work practices are full of tacit unarticulated improvisations. In the case of the Xerox repairmen, when they could not find solutions in the online documentation, they solved a specific problem during face-to-face informal meetings with their colleagues. ${ }^{2}$

A suggestion for a slow face-to-face communication channel could be to include more growers in the already functional interpersonal activities between the scientists and the consultants - and to follow up on the logistical challenge of orchestrating a solution of how to let 10 scientists communicate with 4,500 growers. With the DOI theory in hand, one could argue that the scientists would benefit from limiting the vast number of growers to just a small group of early adopting opinion leaders and letting the existing social networks do the rest as regards diffusing the innovation to the entire seed community.

\section{Conclusion}

We believe the DOI theoretical framework is suitable to explore the Danish seed community, explaining the mechanisms by which the scientific innovation flows through the COP with comparable traits to Rogers' stereotyped adopter categories.

New innovative methods can be implemented faster if the scientists focus more on disseminating scientific knowledge to consultants, advisors, and innovative opinion leading growers via online knowledge media.

For the communications model to become a success in the Danish seed community, it is important to take into consideration the risk of a knowledge gap between fast innovative 
growers and later adopters. If too much emphasis on innovation is put at the front of the communication chain in the growers' community, one risks that the chain will break due to knowledge gaps between faster and slower adopters of innovation. Thus it is vital to focus on both fast and slow learning channels in the community - for instance by combining an online Web2.0 knowledge platform with interpersonal networks in which elements of uncertainty can be discussed and ruled out.

\section{Notes and references}

1 K. Barker (2004), Diffusion of Innovations: a World Tour, J. Health Commun.: International Perspectives 9(6): 131-137.

2 J.S. Brown and P. Duguid (2000), Balancing Act: how to Capture Knowledge without Killing It, Harvard Bus. Rev. May-June: 4-7.

3 J.S. Brown and P. Duguid (2001), Knowledge and Organization: a Social-Practice Perspective, Organ. Sci. 12(2): 198-213.

4 J.S. Brown and P. Duguid (1991), Organizational Learning and Communities-ofPractice: toward a Unified View of Working, Learning, and Innovation, Organ. Sci. 2(1): 40-57.

5 J.W. Creswell (2008), Educational Research - Planning, Conduction, and Evaluating Quantitative and Qualitative Research, 3rd ed., Pearson-Merrill-Prentice Hall, New Jersey, U.S.A.

6 J.W. Dearing, S.M. Greene, W.F. Stewart and A.E. Williams (2011), If We Only Knew What We Know: principles for Knowledge Sharing across People, Practices, and Platforms, Translational Behavioral Medicine 1(1): 15-25.

7 J.W. Dearing (2004), Improving the State of Health Programming by Using Diffusion Theory, J. Health Commun.: International Perspectives 9(6): 21-36.

8 N.K. Denzin and Y. S Lincoln (2005), The Discipline and Practice of Qualitative Research, in The Sage Handbook of Qualitative Research, N.K. Denzin and Y.S. Lincoln eds., Sage Publications, Inc., California, U.S.A., pg. 1-32.

9 P.J. DiMaggio and W.W. Powell (1983), The Iron Cage Revisited: institutional Isomorphism and Collective Rationality in Organizational Fields, Am. Sociol. Rev. 48(2): 147-160.

10 L. Dubé, A. Bourhis and R. Jacob (2006), Towards a Typology of Virtual Communities of Practice, Interdisciplinary Journal of Information, Knowledge, and Management 1(1): 69-93.

11 P. Duguid (2005), "The Art of Knowing”: social and Tacit Dimensions of Knowledge and the Limits of the Community of Practice, The Information Society 21 (2): 109-118.

12 Y. Engeström (2007), From Communities of Practice to Mycorrhizae in Communities of Practice: Critical Perspectives, J. Hughes, N. Jewson and L. Unwin eds., Routledge, London, U.K.

13 R. Hornik (2004), Some Reflections on Diffusion Theory and the Role of Everett Rogers, J. Health Commun.: International Perspectives 9(6): 143-148.

14 D.L. Kincaid (2004), From Innovation to Social Norm: bounded Normative Influence, J. Health Commun.: International Perspectives 9(6): 37-57. 
15 L. Lindkvist (2005), Knowledge Communities and Knowledge Collectivities: a Typology of Knowledge Work in Groups*, J. Manage. Stud. 42(6): 1189-1210.

16 S.R. Melkote (2006), Everett M. Rogers and His Contributions to the Field of Communication and Social Change in Developing Countries, Journal of Creative Communications 1(1): 111-121.

17 S.F. Moseley (2004), Everett Rogers' Diffusion of Innovations Theory: it's Utility and Value in Public Health, J. Health Commun.: International Perspectives 9: 149-151.

18 T. O'Reilly (2007), What Is Web 2.0: design Patterns and Business Models for the Next Generation of Software, Communications \& strategies 1: 17-38.

19 B. Oldenburg and K. Glanz (2008), Diffusion of Innovations, in Health Behavior and Health Education: theory, Research, and Practice, K. Glanz, B.K. Rimer and K. Viswanath eds., Jossey-Bass, Hoboken, U.S.A.

20 G. Orr (2003), Diffusion of Innovations, by Everett Rogers (1995), Stanford University, retrieved 17 February 2012, available at: http://stanford.edu/class/symbsys205/Diffusion\%20of\%20Innovations.htm.

21 E.M. Rogers and A. Singhal (1996), Diffusion of Innovations, in An Integrated Approach to Communication Theory and Research, M.B. Salwen and D.W. Stacks eds., Lawrence Erlbaum Associates, Mahwah, NJ, U.S.A.

22 E.M. Rogers (1995), Diffusion of Innovations, 4th ed., Free Press, Simon \& Schuster, Inc., New York, U.S.A.

23 E.M. Rogers (2003), Diffusion of Innovations. 5th ed., Free Press, Simon \& Schuster, Inc., New York, U.S.A.

24 E.M. Rogers (2004), A Prospective and Retrospective Look at the Diffusion Model, J. Health Commun.: International Perspectives 9(6): 13-19.

25 J. Russell, T. Greenhalgh, P. Boynton and M. Rigby (2004), Soft Networks for Bridging the Gap between Research and Practice: illuminative Evaluation of Chain, BMJ 328(7449): 1174.

26 B. Ryan and N.C. Gross (1943), The Diffusion of Hybrid Seed Corn in Two Iowa Communities, Rural Sociol. 8(1): 15-24.

27 C.A. Savery (2005), Innovators or Laggards: surveying Diffusion of Innovations by Public Relations Practitioners, Master Thesis, University of Akron.

28 W. Smith (2004), Ev Rogers: helping to Build a Modern Synthesis of Social Change, J. Health Commun.: International Perspectives 9(6): 139-142.

29 E.T. Straub (2009), Understanding Technology Adoption: theory and Future Directions for Informal Learning, Rev. Edu. Res. 79(2): 625-649.

30 S. Tveden-Nyborg, M. Misfeldt and B. Boelt (2012), Scientific Knowledge Dissemination in Danish Seed Communities of Practice, JCOM 11(03): A02.

31 B. Wejnert (2002), Integrating Models of Diffusion of Innovations: a Conceptual Framework, Annu. Rev. Sociol. 28: 297-326.

32 E. Wenger (2001), Supporting Communities of Practice - a Survey of Community-Oriented Technologies, retrieved 28 September 2011, available at: http://www.ewenger.com/tech/.

33 E. Wenger, R.A. McDermott and W. Snyder (2002), Cultivating Communities of Practice: a Guide to Managing Knowledge, Harvard Business School Press, Boston, U.S.A. 
34 E. Wenger, N. White and J.D. Smith (2010), Digital Habitats; stewarding Technology for Communities, CPsquare, Portland, U.S.A.

35 E. Wenger (2006), Communities of Practice - a Brief Introduction, retrieved 17 January 2012, available at: http://www.ewenger.com.

36 E. Wenger (1998), Communities of Practice: learning as a Social System, Systems Thinker 9(5): 2-12.

37 E. Wenger (1998), Communities of Practice: Learning, Meaning, and Identity, Cambridge University Press, Cambridge, U.K.

\section{Authors}

Svend Tveden-Nyborg is a Ph.D. candidate at the Faculty of Science and Technology, Department of Agroecology, Aarhus University, Denmark. He is currently involved in research in science communication, in particular scientists disseminating knowledge to the Danish seed community. Svend Tveden-Nyborg has a professional background as an electronic information officer in large-scale international enterprises and thus has a sound knowledge with hands-on web experience and end-user involvement. E-mail: svend.tveden-nyborg@agrsci.dk.

Morten Misfeldt is Associate Professor at Aalborg University - Copenhagen, Denmark. He works with how digital technology changes the infrastructure for scientific and mathematical activity within research and education. E-mail: misfeldt@learning.aau.dk.

Birte Boelt is Senior Scientist at Science and Technology, Department of Agroecology, Aarhus University, Denmark. She is trained in natural sciences and have since 1990 been engaged within seed science. From she has been project leader on large collaborative research programs with the Danish seed community, among those "Establishment of a Danish seed cluster". Birte Boelt is active in science communication with consultants (field days, meetings, conferences) and growers (articles in agricultural press media, field days). E-mail: birte.boelt@agrsci.dk.

How TO CITE: S. Tveden-Nyborg, M. Misfeldt and B Boelt, Diffusing scientific knowledge to innovative experts, JCOM 12(01) (2013) A03. 